\title{
Multidisciplinary family-centred psychosocial care for patients with CHD: consensus recommendations from the AEPC Psychosocial Working Group ${ }^{*}-$ ERRATUM
}

Elisabeth M.W.J. Utens, ${ }^{1,2}$ Edward Callus, ${ }^{3,4}$ Eveline M. Levert, ${ }^{1}$ Katya De Groote, ${ }^{5}$ Frank Casey ${ }^{6}$

DOI: https://doi.org/10.1017/S1047951117001378, Published online: 11 September 2017

First published online: 27 November 2017

The publisher apologises for errors in the affiliations for the authors given on page 1 of the article. The correct information is as follows:

Elisabeth M.W.J. Utens, ${ }^{1,2} * \quad$ Edward Callus, 3,6 Eveline M. Levert, ${ }^{1}$ Katya De Groote, ${ }^{4}$ Frank Casey ${ }^{5,6}$

\section{Reference}

Elisabeth M.W.J. Utens, Edward Callus, Eveline M. Levert, Katya De Groote, Frank Casey. Multidisciplinary family-centred psychosocial care for patients with CHD: consensus recommendations from the AEPC Psychosocial Working Group. Cardiol Young. Published by Cambridge University Press, 11 September 2017. DOI: https://doi.org/10.1017/ S1047951117001378. 